\title{
A leitura no espaço carcerário
}

\section{Elionaldo Fernandes Juliáo*}

Jane Paiva**

\section{Resumo}

A leitura no Brasil tem sido objeto de estudos e de controvérsias. Levando em consideração as diversas questóes que envolvem a discussão do tema no país, o artigo tem como objetivo apresentar algumas reflexôes sobre a política de leitura implementada no sistema penitenciário nacional. Nesse contexto, o incentivo à leitura tem sido considerado pelo poder público, assim como a educação escolar, como um dos meios alternativos para a socializaçáo do preso. Dessa forma, este artigo, em síntese, apresenta questôes e reflexôes sobre o papel e os significados que a leitura pode assumir no sistema penitenciário e procurará analisar os principais encaminhamentos políticos na área da leitura voltados ao cárcere, destacando, entre outros, fontes legais, projetos e perspectivas político-pedagógicas no contexto atual.

Palavras-chave: Educação de Jovens e Adultos. Restrição e privação de liberdade. Políticas de leitura.

\footnotetext{
* Doutor em Ciências Sociais pela Universidade do Estado do Rio de Janeiro (UERJ). Professor e pesquisador em Educação de Jovens e Adultos do Instituto de Educação de Angra dos Reis (IEAR) e do Programa de Pós-Graduação em Educação da Universidade Federal Fluminense (UFF). ** Doutora em Educação pela Universidade Federal Fluminense (UFF). Professora e pesquisadora da Faculdade de Educação e do Programa de Pós-Graduação em Educação da Universidade do Estado do Rio de Janeiro (UERJ) no campo da Educação de Jovens e Adultos.
} 


\section{Contextualizando a problemática}

A leitura no Brasil tem sido objeto de estudos e de controvérsias. Se, por um lado, o incentivo à leitura a partir de políticas de distribuição de livros, especialmente por meio de programas federais, possa indicar a disseminação do objeto livro - e poder-se-ia dizer, da obra literária — para significativa parcela da populaçáo, principalmente as que se vinculam a escolas públicas de todos os níveis e modalidades, por outro, o mercado editorial que cresce em número de publicaçôes de qualidade editorial, de eventos com sucesso de público, queixa-se da pequena venda, o que justificaria tiragens de 2.000 exemplares, no máximo, para um conjunto restrito dos (mesmos) consumidores.

Nas escolas, a discussão da leitura ofertada de modo coletivo - por meio de bibliotecas/salas de leitura ou qualquer outro nome que se dê ao espaço físico em que ficam abrigados os livros desses programas — ainda é frágil, e poucas vezes está incorporada ao projeto político pedagógico, e com pouca expressão nas práticas pedagógicas de professores e na vida acadêmica de alunos, como demonstram pesquisas realizadas para avaliar o Programa Nacional Biblioteca da Escola (PNBE), em 2005 (BRASIL, 2005), e para diagnosticar a situação das bibliotecas escolares no Brasil, em 2009 (BRASIL, 2009b). O que dizer, então, do espaço fechado, encerrado em seus próprios muros, que representam os presídios e instituiçôes socioeducativas?

Diante das exigências de leitura no mundo atual, a escola, mesmo não sendo a única instituição por ela responsável, assume importante papel na formação de leitores e neoleitores, que avancem da condição de usuários da língua escrita. Especialmente quando se trata de democratização da educação e da cultura, em país ainda tão desigual, o papel da escola é insubstituível, por se tratar de instituição das mais democratizadas da sociedade brasileira, pelo acesso que vem garantindo, ao menos no nível do ensino fundamental, para mais de $97 \%$ das crianças. Se crianças nessa faixa de ensino vão à escola, pode-se ter a certeza de que, em torno dela, circulam famílias e adultos, ou seja, o papel indutor da leitura na e a partir da escola para toda a sociedade é potencial e potente.

Para os jovens e adultos em situação de restrição e privação de liberdade, nos últimos anos, vários são os encaminhamentos legais que vem sendo discutidos e implementados para a consolidação de uma política nacional que garanta o direito a educação, previsto na Lei de Execuções Penais. Dentre eles, 
destacam-se a aprovação das Resoluções do Conselho Nacional de Política Criminal e Penitenciária (CNPCP) n. 3, de 11 de março de 2009 (BRASIL, 2009a), e do Conselho Nacional de Educação (CNE) n. 2, de 19 de maio de 2010 (BRASIL, 2010), que regulamentam as Diretrizes Nacionais para a oferta de educação nos estabelecimentos penais. Em ambas Resoluções, além da elevação de escolaridade, a leitura é considerada como fundamental no processo educativo, sendo um dos meios alternativos para a ressocialização do preso.

Concordando com Antônio Carlos Gomes da Costa (PROMENINO, 2003), as políticas de restrição e privação de liberdade no mundo são o "terreno baldio da falta de um conjunto mais adequado de normas infralegais", o que não deixa escapar o Brasil, pois as políticas implementadas para a área não estấo consolidadas como políticas de Estado, mas sim como açôes de governo, muitas vezes descontínuas e contextualizadas em diversos projetos pontuais que se justificam em si mesmo.

Saídas como se fossem de uma cartola de mágico, a cada ano novas ideias, transformadas em projetos e programas, são apresentadas pelo poder público e pela sociedade civil organizada como inovaçóes e possíveis respostas para resolver questôes no âmbito das políticas de execução penal e socioeducativa.

Em abril de 2008, o Departamento Penitenciário Nacional (DEPEN) do Ministério da Justiça aprovou, em parceria com os 27 estados da federação, o Plano Diretor do Sistema Penitenciário ${ }^{1}$, composto de 22 metas definidas pela União e que abrangem, de forma ampla, as necessidades existentes no Sistema, para que se possa reestruturar o atual modelo penitenciário.

O Plano visa a alcançar o compromisso dos estados com o investimento em diversas açóes de âmbito político e administrativo, almejando como resultado "um sistema mais humano, seguro e que atenda à legalidade quanto ao tratamento básico a ser dispensado à pessoa em situação de encarceramento" (BRASIL, 2008c).

Entre as 22 metas, uma delas estimula que os estados promovam nos estabelecimentos penais a criação de bibliotecas, afirmando: "o incentivo à leitura tem sido considerado um dos meios alternativos para a ressocializaçáo do preso. Ele passa a ocupar melhor o tempo e a desenvolver um raciocínio crítico sobre o mundo em que vive." (BRASIL, 2008c).

Seguindo nesta mesma direçáo, após aprovada a Lei que regulamenta a remição pela educação, o DEPEN resolveu aprovar uma Portaria que disciplina o Projeto da Remiçẫo pela Leitura no Sistema Penitenciário Federal. 
Levando em consideração as principais questóes abordadas nesta introdução, assim como uma série de outras de ordem empírica, vivenciadas pelos autores ao longo de vários anos de experiência com estudos e pesquisas em educação de jovens e adultos, leitura e bibliotecas, assim como realizando açôes educativas no sistema penitenciário, este artigo apresenta questóes e reflexōes sobre o papel e significados que a leitura pode assumir no sistema penitenciário. O presente artigo procurará, ainda, analisar os principais encaminhamentos políticos na área da leitura voltados ao sistema penitenciário, destacando, entre outros, fontes legais, projetos e perspectivas político-pedagógicas no contexto atual.

\section{Projetos de leitura no sistema penitenciário}

Desde 1984, conforme definido pelo Art. 21 da Lei de Execução Penal (LEP) (BRASIL, 1984), "em atendimento às condiçôes locais, dotar-se-á cada estabelecimento de uma biblioteca, para uso de todas as categorias de reclusos, provida de livros instrutivos, recreativos e didáticos". Ou seja, a perspectiva de dotar instituiçôes penais de recursos materiais da cultura vem da aprovação do instrumento mais forte de disciplinamento do cárcere e das formas de vivenciar a privação de liberdade, não nasce separado, nem de forma estanque, já fora previsto no conjunto legal que conforma o aparato ordenador da administração penitenciária.

Entretanto, dos mais de 1.100 estabelecimentos penais existentes no Brasil, poucos possuem espaços infraestruturais, como previsto para a realização de atividades educacionais, culturais, esportivas e de lazer.

Somente em 2011, com a aprovação pelo Conselho Nacional de Política Criminal e Penitenciária (CNPCP) da Resolução n. 9, de 18 de novembro de 2011 (BRASIL, 2011a), estabelecem Diretrizes Básicas para a Arquitetura Penal. A referida Resolução tem como objetivo: definir orientaçōes gerais para a construção, ampliação e reforma de estabelecimentos penais, principalmente em parceria com o governo federal; determinar normas para a apresentação de projetos de construção, ampliação e reforma de estabelecimentos penais e para a celebração de convênios com a União; conceituar e classificar estabelecimentos penais; elaborar projetos arquitetônicos e projetos específicos - tipologia arquitetônica; além de apresentar a conceituação para projetos de arquitetura e engenharia de estabelecimentos penais. 
O documento, embora com várias lacunas, é considerado importante avanço na proposta política de execução penal, principalmente no que diz respeito a políticas mais humanas de execução penal, que não somente valorizam a segurança a qualquer custo, mas também respeitam direitos dos apenados, reconhecendo-os como sujeitos de direitos.

Defende, ainda, a necessidade de se resguardarem as características de cada estabelecimento penal ${ }^{2}$. Segundo o documento, "os projetos deveráo prever, conforme o caso e o uso a que se destina o estabelecimento, os módulos conforme o programa de necessidades" (BRASIL, 2011a).

Quanto ao "módulo educativo", por exemplo, o documento prevê sua existência obrigatória nas penitenciárias, nas colônias agrícolas, industriais ou similares e cadeias públicas. Esses módulos são compreendidos como "espaços destinados às atividades de ensino formal, informal e profissionalizante e atividades da comunidade com as pessoas presas" (BRASIL, 2011a). Entre eles, é prevista a construção de bibliotecas ${ }^{3}$, com área mínima de $30 \mathrm{~m}^{2}$

Durante a elaboração dos Planos Diretores das Unidades da Federação ${ }^{4}$, um breve levantamento foi realizado sobre a situação de bibliotecas no Sistema Penitenciário. Segundo o relatório da situação atual do sistema penitenciário (BRASIL, 2008c), dos 1.148 estabelecimentos penais existentes nos estados pesquisados, apenas 305 possuíam bibliotecas. Segundo o documento:

[...] o acervo disponibilizado aos presos é limitado e em regra, foi formado através de campanhas de doação de livros fornecidos pela comunidade e por instituiçóes públicas e privadas. Os livros, na sua maioria, são didáticos e de literatura variada. A principal dificuldade para a criação das bibliotecas é a falta de espaço físico nas unidades penais. Em Minas Gerais, foi implantado o Projeto Sala de Leitura que prevê a criaçáo de salas de leitura, bem como a doação de 1.000 livros para os estabelecimentos penais do Estado. O Instituto Oldemburg de Desenvolvimento realizou importantes doaçóes às unidades penais, nos estados do Rio de Janeiro, Pernambuco e Espírito Santo. (BRASIL, 2008c, p. 27).

A Tabela 1 apresenta a distribuição de bibliotecas em unidades prisionais, por estado: 
Tabela 1 - Unidades prisionais, por estado, que possuem bibliotecas

\begin{tabular}{|c|c|c|}
\hline UF/Regiáo & $\begin{array}{c}\text { Número de } \\
\text { unidades }\end{array}$ & $\begin{array}{c}\text { Número de unidades que } \\
\text { possuem bibliotecas }\end{array}$ \\
\hline $\mathrm{AC}$ & 13 & 1 \\
\hline AM & 17 & 2 \\
\hline $\mathrm{AP}$ & 5 & 2 \\
\hline PA & 37 & 2 \\
\hline $\mathrm{RO}$ & 38 & 1 \\
\hline RR & 5 & 2 \\
\hline $\mathrm{TO}$ & 22 & 3 \\
\hline NORTE & 137 & 13 \\
\hline $\mathrm{AL}$ & 8 & 2 \\
\hline $\mathrm{BA}$ & 22 & 14 \\
\hline $\mathrm{CE}$ & 144 & 5 \\
\hline MA & 12 & 1 \\
\hline PB & 82 & 6 \\
\hline PE & 86 & 4 \\
\hline PI & 14 & 6 \\
\hline $\mathrm{RN}$ & 13 & 8 \\
\hline SE & 6 & 3 \\
\hline NORDESTE & 387 & 49 \\
\hline DF & 6 & 6 \\
\hline $\mathrm{GO}$ & 70 & 11 \\
\hline MS & 38 & 1 \\
\hline MT & 63 & 4 \\
\hline $\begin{array}{l}\text { CENTRO- } \\
\text { OESTE }\end{array}$ & 177 & 22 \\
\hline ES & 22 & 4 \\
\hline MG & 67 & 27 \\
\hline $\mathrm{RJ}$ & 44 & 16 \\
\hline SP & 146 & 110 \\
\hline SUDESTE & 279 & 157 \\
\hline PR & 25 & 13 \\
\hline $\mathrm{RS}$ & 92 & 46 \\
\hline SC & 50 & 5 \\
\hline SUL & 167 & 64 \\
\hline TOTAL & 1148 & 305 \\
\hline
\end{tabular}

Fonte: Plano Diretor do Sistema Penitenciário (Bibliotecas) (BRASIL, 2008c; INFOPEN, 2008).

A criação de salas de leitura e de bibliotecas no sistema penitenciário vem sendo incentivada há décadas pelo poder público, organizaçôes da sociedade 
civil e, principalmente, Organizaçóes Não-Governamentais (ONGs), que têm como missão o incentivo à leitura.

Na história da política de execução penal brasileira, é frequente a realização de campanhas estaduais e nacionais com o objetivo de arrecadar livros para serem utilizados em projetos de leitura no sistema penitenciário. Do acervo existente, a maior parte é fruto de doações. Pouco efetivamente corresponde à aquisição por meio de compras específicas de obras para bibliotecas e salas de leitura existentes no sistema penitenciário.

Em 2008, por exemplo, o Ministério da Justiça, em parceria com o Conselho da Justiça Federal, a Comissão de Direitos Humanos da Câmara dos Deputados e do Movimento Nacional dos Direitos Humanos, realizou uma campanha nacional que arrecadou, no país, mais de 10 mil livros dos mais variados gêneros, como romance, crônica, autoajuda, ficção, história e literatura estrangeira. Não vem sendo diferente nos estados brasileiros. Várias são as experiências governamentais e não governamentais que incentivam a realização de campanhas pontuais de arrecadação de livros para o sistema penitenciário.

O Plano Diretor Estadual, ao estabelecer metas para os sistemas penais estaduais, atendendo o Art. 21 da LEP, institui a criação de espaços literários e formação de acervos em todas as unidades penais. Cada estado, em decorrência, estabeleceu um Plano Diretor com metas quanto ao tema, e vários se comprometeram com a proposta de criação desses espaços.

O Programa Nacional de Segurança Pública com Cidadania (Pronasci) ${ }^{5}$, do Ministério da Justiça, também previu a construção de presídios específicos para jovens adultos (de 18 a 24 anos) e para mulheres nas regióes mais violentas do país $^{6}$. Essas unidades devem contar com bibliotecas, brinquedotecas, salas de aula e cursos profissionalizantes e educacionais.

Infelizmente, a ausência de uma cultura de acompanhamento e avaliação de políticas públicas no Brasil não tem possibilitado verificar se há resultados concretos em relação às açôes previstas e realizadas nesta direção. As informações são imprecisas e não fundamentadas, impossibilitando avaliaçôes mais objetivas sobre o tema. Outro aspecto a lamentar é que a política visa tentar minimizar problemas do encarceramento de jovens e mulheres - em número que cresce progressivamente -, sem buscar equacionar, nem reverter, as possíveis origens de tantos encarceramentos entre estes públicos. Pode-se, talvez, supor, como Loïc Wacquant (2011), que a rota escolhida pelo Brasil, como tantos países 
assaltados pelo modelo capitalista neoliberal foi a de "criminalizar a pobreza", investindo mais nas "prisóes da miséria" do que nos processos de origem econômica e social que a determinam.

\section{É possível pensar a privação de liberdade de forma educativa? O que dizem alguns documentos oficiais}

\section{Resolução n. 2 do Conselho Nacional de Educação}

Conforme Resolução n. 2, de 19 de maio de 2010, que dispóe sobre "Diretrizes Nacionais para a oferta de educação para jovens e adultos em situação de privação de liberdade nos estabelecimentos penais", no Art. $3^{\circ}$, inciso III, pode-se ler:

[...] a oferta de educação para jovens e adultos em estabelecimentos penais [...] estará associada às açôes complementares de cultura, esporte, inclusão digital, educação profissional, fomento à leitura e a programas de implantaçấo, recuperação e manutenção de bibliotecas destinadas ao atendimento à população privada de liberdade, inclusive as ações de valorização dos profissionais que trabalham nesses espaços. (BRASIL, 2010).

Como se observa, o atendimento previsto a jovens e adultos privados de liberdade não espera do poder público uma simples ação de escolarização, mas a ele associam-se açóes integradas de esporte, cultura e educaçáo profissional, pensando a formação e o desenvolvimento humanos, de modo amplo.

Portaria que disciplina o Projeto da Remição pela Leitura no Sistema Penitenciário Federal

Em 20 de junho de 2012, a Corregedoria-Geral da Justiça Federal e o Departamento Penitenciário Nacional publicaram Portaria conjunta (n. 276, de 20 de junho de 2012), que disciplina o Projeto Remição pela Leitura no Sistema Penitenciário Federal ${ }^{8}$. No Art. $1^{\circ}$, a Portaria "institui, no âmbito das Penitenciárias Federais, o Projeto 'Remição pela Leitura', em atendimento ao 
disposto na Lei de Execução Penal, no que tange à Assistência Educacional aos presos custodiados nas respectivas Penitenciárias Federais" (BRASIL, 2012b).

Segundo o documento, prevê-se:

Art. 3: A participação do preso dar-se-á de forma voluntária, sendo disponibilizado ao participante 1 exemplar de obra literária, clássica, científica ou filosófica, dentre outras, de acordo com as obras disponíveis na Unidade, adquiridas pela Justiça Federal, pelo Departamento Penitenciário Nacional e doadas às Penitenciárias Federais. (BRASIL, 2012b).

Para a sua efetivação, a portaria ainda prevê que será necessária a existência de acervos com, no mínimo, 20 exemplares de cada obra a serem trabalhadas no Projeto, nas bibliotecas das Penitenciárias Federais.

Conforme o Art. $4^{\circ}$ do Projeto Remiçáo pela Leitura, o preso terá um prazo de 21 a 30 dias para a leitura de uma obra literária, com a apresentação, ao final deste período, de resenha sobre a obra lida, o que possibilitará, segundo critério legal de avaliação, a remição de 4 dias da pena. Ao final de até 12 obras lidas e avaliadas, terá, de acordo com a capacidade gerencial da Unidade, a possibilidade de remir 48 dias, no prazo de 12 meses.

Poderão participar do Projeto todos os presos que tenham, segundo o inciso III do Art. 6०, "as competências de leitura e escrita necessárias para a execução das atividades referentes ao mesmo, principalmente aqueles que não estiverem sendo atendidos pela escola regular ou por outras oficinas/ projetos extracurriculares" (BRASIL, 2012b). Ou seja, o Projeto se apresenta como alternativa, principalmente, para unidades que náo conseguem oferecer atividades escolares/educativas regulares aos internos penitenciários.

Quanto à organização e ao acompanhamento do Projeto na unidade, está previsto que serão de responsabilidade do pedagogo ou, na sua ausência, de servidor designado pelo chefe da Divisão de Reabilitação da respectiva Unidade. Para a análise das resenhas de obras lidas, nesse caso, deverá ser constituída comissão, observando aspectos relacionados à compreensão e à compatibilidade do texto redigido com o teor da obra lida.

É importante destacar, ainda, na análise do documento, que a política de execução penal de remição pela leitura, implementada nos presídios federais, 
restringe sua aplicação ao "Regime Disciplinar Diferenciado" (RDD) ${ }^{9}$, em que o interno passa a viver isolado em alojamento individual, sem qualquer contato com os demais.

A referida Portaria restringe-se, ainda, a Unidades Penais Federais, mas vai ao encontro e complementa o já previsto na Lei n. 12.433, de 29 de julho de 2011, que "altera a Lei n. 7.210, de 11 de julho de 1984 (Lei de Execução Penal), para dispor sobre a remição de parte do tempo de execução da pena por estudo ou por trabalho" (BRASIL, 2011b). Ao dar condiçôes para que apenados, em regime fechado e semiaberto, possam também remir pelo estudo, parte do tempo da execução da pena, a lei considera o direito à educação a todos os sujeitos, premiando, aqueles que disponham seu tempo para cumprir processos escolares inconclusos ou interrompidos, como aposta do poder da educação para a formação humana.

Para a contagem da remição pelo estudo, esta será feita à razão de "1 dia de pena a cada 12 horas de frequência escolar - atividade de ensino fundamental, médio, inclusive profissionalizante, ou superior, ou ainda de requalificação profissional - divididas, no mínimo, em 3 dias" (inciso I do $\$ 1^{\circ}$ do Art. 126 da LEP), ou seja, não está previsto, pela LEP, o benefício para açóes educativas não regulares implementadas nas diversas unidades penais, inclusive as de leitura. Entretanto, a "remição será declarada pelo juiz da execução, ouvidos o Ministério Público e a defesa” ( $\$ 8^{\circ}$ do Art. 126 da LEP) que poderá, de acordo com interpretação própria, considerar ou não as demais ações não previstas em lei como educativas e passíveis de contagem para a remição.

Em síntese, pode-se afirmar que ainda se carece de estratégias alternativas para a implementação de ações de tratamento penitenciário previstas na Lei de Execução Penal, pois, independentemente de questôes de segurança que envolvem a discussão sobre os diversos tipos de regime de privação de liberdade, o que está em jogo é o fato de os internos penitenciários continuarem a ser sujeitos de direitos, condição não subtraída pela condenação ou pela pena a eles imposta, o que implica, consequentemente, o dever (do Estado) em assegurar esses direitos, especialmente quando se encontram sob sua tutela.

\section{Tecendo algumas ideias (in)conclusivas}

Muitas questôes estấo envolvidas quando se trabalha no terreno de políticas para sujeitos privados da liberdade. Uma das mais sérias diz respeito 
ao imaginário social para o qual náo basta o cumprimento da pena, cabendolhe sempre o dedo acusatório sobre qualquer política, como expressão do que considera privilégio.

No estado de direito, entretanto, assegurar condiçóes de justiça e igualdade a todos, sujeitos livres e privados de liberdade, implica percorrer um longo caminho, tanto para uns como para outros. A desigualdade no acesso a bens e direitos para todos, vivida pelas classes sociais desprivilegiadas na hierarquia de classes, no modo de produção capitalista, torna os livres não tão livres, porque viventes, no jugo da opressão econômica e social, e diferentes, capazes de serem julgados como desiguais pela condição de inferioridade de classe. Ora, em um sistema assim promotor de desigualdades, como esperar que os não livres possam ser considerados sujeitos de direito, se muitos dos que são livres sequer o são?

O desafio a ser enfrentado quando se lida com questóes educativas - e políticas - que envolvem sujeitos em situação de restrição e privação de liberdade é fortemente acentuado e segue instigando formas de pensar, de agir e de transformar a realidade que ajuda a produzir sujeitos táo desiguais.

A educação para todos, independente da idade, como direito social e conquista democrática que se estabelece na Constituiçáo Brasileira de 1988 (BRASIL, 1988), e, ainda, como direito humano fundamental, preconizado pela Declaraçáo dos Direitos Humanos de 1948, não tem sido traduzida como política pública efetiva para todos os cidadãos brasileiros. Para muitos, de geraçôes mais velhas, sua interdição se fez pelo déficit de oferta escolar no tempo da infância, e, para muitos outros, vem se fazendo como parte dos processos excludentes que tratam desigualmente os diferentes, considerando "natural" que alguns poucos aprendam e tenham sucesso, enquanto muitos vão sendo condenados ao fracasso, ao insucesso escolar, à não aprendizagem que a escola reconhece como válida. Nessa arquitetura terrível do percurso escolar, a leitura e a escrita têm sido responsabilizadas como ferramentas intransponíveis para muitos, privados do acesso a bens culturais que conformam os modos de viver da cultura escrita, em sociedades que por ela se organizam.

O direito de ler e escrever não assegurado na infância atravessa, por assim dizer, as demais políticas públicas, cuja abrangência imbrica-se diretamente com os requerimentos e processos desencadeados por essas ferramentas poderosas da vida social, das quais nenhum sujeito pode permanecer afastado. 
No caso do Brasil, o número absoluto de pessoas sem escolarização nos diferentes níveis e etapas da educação básica vai-se somando de forma perversa, até alcançar o dado de 101 milhôes de brasileiros sem a educaçâo básica concluída, ou seja, sem a conclusão do ensino médio. Transposto para a realidade do cárcere, o dado se acentua perversamente, reforçando a tese de Wacquant (2011) sobre as Prisóes da miséria, resultantes de um sistema injusto, que pune ainda mais intensamente determinadas classes sociais.

Projetos de leitura, portanto, são bem vindos, isoladamente ou associados a programas regulares de escolarização, para que se cumpra, nas condiçóes disponíveis durante o tempo de privaçáo de liberdade dos sujeitos, o direito de aprender não efetivado no tempo da infância. Mas também que os projetos possam se efetivar pelo mistério que a leitura pode operar nos sujeitos, e não como resultado de avaliaçôes sobre o que foi compreendido das obras, cujo valor polissêmico não lhes permite um - e só um - único sentido. Este éo risco de avaliaçôes negativas de resenhas julgadas por comissóes, no mais das vezes despreparadas sobre o que é ler/interpretar.

Se nem a leitura, nem a educação, podem ser vistas como projeto salvacionista, entretanto, afirma-se que a primeira pode, sim, libertar pela capacidade imaginativa que possibilita e pelo poder de criar situaçóes imaginadas, transportar cada sujeito para novos voos, pela densidade de narrativas e prosas que bons autores produzem, no conjunto de obras literárias à disposição de bons acervos e boas bibliotecas.

Que venham os livros, os textos, os acervos, as bibliotecas para os espaços do cárcere, ainda que se saiba que livros e obras, sozinhos, em estantes, não operam mudanças, nem se fazem ler sem a ação dos sujeitos sobre eles. Para isso, pensar projetos de leitura que distribuem livros exige pensar em concomitância uma ação dinamizadora, essencial como mediação que aproxima e apresenta o sujeito a cada percurso ficcional, instigando o desejo e a curiosidade de desvendar os mistérios que cada obra encerra.

\section{Notas}

${ }^{1}$ Segundo o Departamento Penitenciário Nacional, do Ministério da Saúde (DEPEN/MJ), o Plano Diretor do Sistema Penitenciário corresponde a um mecanismo de planejamento que contém um conjunto de açóes a ser implementado, pelas Unidades Federativas, em curto, 
médio e longo prazos, visando o cumprimento dos dispositivos contidos na Lei n. 7.210/84 (BRASIL, 1984), e nas diretrizes da política criminal emanadas do Conselho Nacional de Política Criminal e Penitenciária. Visa, ainda, o fortalecimento institucional e administrativo dos órgãos de execução penal locais, em busca de um sistema mais humano, seguro e que atenda à legalidade quanto ao tratamento básico a ser dispensado à pessoa em situação de encarceramento.

${ }^{2}$ Estabelecimentos penais são todos aqueles utilizados pela Justiça com a finalidade de alojar ou atender pessoas presas, quer provisórias, quer condenadas, ou ainda aquelas que estejam submetidas à medidas de segurança. As cadeias públicas ou estabelecimentos congêneres, por exemplo, são estabelecimentos penais destinados ao recolhimento de pessoas presas em caráter provisório. As penitenciárias são estabelecimentos penais destinados ao recolhimento de pessoas presas com condenaçáo à pena privativa de liberdade em regime fechado, dotadas de celas individuais e coletivas. As colônias agrícolas, industriais ou similares são estabelecimentos penais destinados a abrigar pessoas presas que cumprem pena em regime semiaberto. As casas do albergado são estabelecimentos penais destinados a abrigar pessoas presas que cumprem pena privativa de liberdade em regime aberto, ou pena de limitação de fins de semana. Os centros de observação criminológica são estabelecimentos penais de regime fechado e de segurança máxima onde devem ser realizados exames, cujos resultados serão encaminhados a Comissões Técnicas de Classificação, que indicarão o tipo de estabelecimento e o tratamento adequado para cada pessoa presa, a eles submetidas. Os hospitais de custódia e tratamento, também denominados serviço de atençáo ao paciente judiciário, são estabelecimentos penais destinados a atender pessoas submetidas a medidas de segurança. Levando em consideração características de cada regime - o semiaberto e o aberto, por exemplo as atividades de serviços podem ser realizadas fora do estabelecimento penitenciário. Nesse caso, os espaços destinados a esse fim podem ser suprimidos do projeto arquitetônico.

${ }^{3}$ É prevista a construção de bibliotecas e salas de aula também nos Centros de Observação Criminológica.

${ }^{4}$ Período de outubro de 2007 a abril de 2008. 
${ }^{5} \mathrm{O}$ Pronasci é uma iniciativa que propõe reunir ações de prevenção, controle e repressão da violência com atuação focada nas raízes socioculturais do crime. Articula programas de segurança pública com políticas sociais já desenvolvidas pelo governo federal, sem abrir mão das estratégias de controle e repressão qualificada à criminalidade. As ações desenvolvidas pelo Pronasci propóem ainda diretrizes estabelecidas pelo Sistema Único de Segurança Pública, cujo eixo central é a articulação entre a União, os estados e municípios para o combate ao crime.

${ }^{6}$ O Programa prevê, para o Sistema Prisional, a criação de 41 mil novas vagas para homens e 5,4 mil para mulheres, ampliando o atendimento educacional, profissionalizante e de cidadania. Serão investidos sete milhóes de reais para estabelecimento penal feminino, criando diretamente 256 novas vagas, e 12 milhóes de reais para estabelecimento penal masculino voltado a jovens entre 18 e 24 anos, criando 421 novas vagas.

${ }^{7}$ As Diretrizes são fruto de diversas açóes coordenadas pelos Ministérios da Justiça e da Educação, em articulaçáo com os estados e com a sociedade civil organizada, a partir de 2005, sobre a "educação em prisóes", demandando para os Conselhos Nacional de Educação (CNE) e de Política Criminal e Penitenciária (CNPCP) os devidos encaminhamentos para aprovação. Por meio da Resolução n. 3, de 11 de março de 2009, o CNPCP aprovou as Diretrizes Nacionais para a oferta de educaçáo nos estabelecimentos penais no âmbito da política de execução penal. Por sua vez, o CNE aprovou, pela Resoluçáo n. 2, de 19 de maio de 2010, as Diretrizes Nacionais para a oferta de educação para jovens e adultos em situação de privação de liberdade no âmbito das políticas de educação.

${ }^{8}$ No Art. $2^{\circ}$, "o Projeto visa à possibilidade de remição da pena do custodiado em regime fechado, em conformidade com o disposto no artigo 126 da Lei n. 7.210, de 11 de julho de 1984, alterado pela Lei 12.433/2011, de 29 de junho de 2011, concomitantemente com a Súmula 341 do STJ, com o Art. 3º, III da Resolução n. 02 do Conselho Nacional de Educação e com o Art. 3º, IV da Resolução n. 03 do Conselho Nacional de Política Criminal e Penitenciária, o qual associa a oferta da educação às açóes complementares de fomento à leitura, atendendo a pressupostos de ordem objetiva e outros de ordem subjetiva" (BRASIL, 2012b). 
${ }^{9}$ O Regime Disciplinar Diferenciado (RDD) é objeto da Lei n. 10.792 (BRASIL, 2012b), que alterou a Lei de Execuçôes Penais e o Código de Processo Penal no país. A Lei prevê sua aplicação para o interno que estiver cumprindo pena por condenação ou estiver temporariamente em reclusão. Neste regime, o preso é mantido em cela individual 22 horas por dia, podendo ser visitado por até duas pessoas em uma semana, tomando um banho de sol por dia, de duas horas no máximo. Não é permitido ao preso manter qualquer contato com o mundo externo, principalmente ter acesso a jornais ou televisão. É previsto que o preso fique sob este regime por 360 dias, podendo o período ser renovável por mais dias, mas não podendo exceder $1 / 6$ da pena a ser cumprida, quando entáo deverá retornar ao regime prisional tradicional.

\section{REFERÊNCIAS}

BRASIL. Lei 7.210, de 11 de julho de 1984. Institui Lei de Execução Penal. Diário Oficial da União, Brasília, DF, 13 jul. 1984. 1988

Constituição da República Federal do Brasil de 1988. Brasília, DF,

. Avaliação Diagnóstica do Programa Nacional Biblioteca da Escola (PNBE). Rio de Janeiro: UERJ, 2005. (Relatório de Pesquisa).

. Departamento Penitenciário Nacional. Manual de Diretrizes Gerais e Procedimentos Operacionais. Brasília: MJ/DEPEN, 2008a.

Ministério da Justiça. Departamento Penitenciário Nacional. Relatório da situação atual do sistema penitenciário: educação e profissionalização. Brasília: MJ/DEPEN, 2008b.

Ministério da Justiça. Departamento Penitenciário Nacional. Relatório da situação atual do sistema penitenciário: bibliotecas. Brasília: MJ/ DEPEN, 2008c.

Ministério da Justiça. Programa Nacional de Segurança Pública com Cidadania (Pronasci). Brasília, DF, 2008d. 
BRASIL. Ministério da Justiça. Conselho Nacional de Política Criminal e Penitenciária. Resolução n. 3, de 11 de março 2009. Dispôe sobre as Diretrizes Nacionais para a Oferta de Educação nos estabelecimentos penais. Diário Oficial da União, Brasília, DF, 25 mar. 2009a.

Ministério da Educação. Organização dos Estados Iberoamericanos para a Educação. Relatório de pesquisa Avaliação de bibliotecas escolares no Brasil. Rio de Janeiro: UERJ, 2009b.

Ministério da Educação. Conselho Nacional de Educação. Câmara de Educação Básica. Resolução no 2, de 19 de maio de 2010. Dispóe sobre as Diretrizes Nacionais para a oferta de educação para jovens e adultos em situaçáo de privação de liberdade nos estabelecimentos penais. Diário Oficial da Uniāo, Brasília, DF, 20 maio 2010. Seção 1. p. 20.

Ministério da Educação. Departamento Penitenciário Nacional. Conselho Nacional de Política Criminal e Penitenciária. Diretrizes Básicas para arquitetura penal. Brasília: MJ/DEPEN/CNPCP, 2011.

Ministério da Educação. Departamento Penitenciário Nacional. FUNPEN em Números. Brasília: MJ/DEPEN, 2012a.

Departamento Penitenciário Nacional. Portaria Conjunta no 276, de 20 de junho de 2012. Disciplina o Projeto da Remição pela Leitura no Sistema Penitenciário Federal. Diário Oficial da União, Brasília, DF, 22 jun. 2012b.

PROMENINO. Fundação Telefônica. Conversando sobre a política de atendimento do ECA. Uma entrevista com Antonio Carlos Gomes da Costa. 2003. Disponível em: <http://www.promenino.org.br/portals/0/cidade/ cidade_final/entrevista.doc $>$.

WACQUANT, Loïc. As prisôes da miséria. Rio de Janeiro: Jorge Zahar, 2011. 


\section{La lectura en el espacio del cárcel}

\section{Resumen}

La lectura en Brasil es un objeto de estudios y de controversias. Con todas las diversas cuestiones que involucran la discusión del tema en el país, el artículo tiene como meta presentar algunas reflexiones sobre la política de lectura implementada en el sistema penitenciario nacional. En ese contexto, el estímulo a la lectura ha sido considerado por el poder público, y también por la educación escolar, cómo uno de los medios alternativos para la socialización del preso. De esa forma, el artículo, presenta cuestiones y reflexiones sobre el papel y los significados que la lectura puede asumir en el sistema penitenciario y buscará analizar las principales opciones políticas en la área de la lectura en la cárcel, destacando, entre otros aspectos, fuentes legales, proyectos y perspectivas político pedagógicas existentes en el contexto actual.

Palabras claves: Educación de jóvenes y adultas. Restricción y privación de libertad. Lectura en la cárcel. Políticas de lectura.

\section{Reading in prison}

\begin{abstract}
In Brazil reading has been the subject of study and controversy. Taking into account the various issues which involves the discussion of the subject in the country, the article aims to present some reflections on the reading policy implemented at the national penitentiary system. In this context, the motivation to reading has been considered by the government as well as school education, an alternative to the rehabilitation and socialization of prisoners. This article, in short, presents questions and reflections on the role and meanings that reading can take in the prison system and it seeks to examine the major political forwards in the reading area which have its goals to the prison facing the prison, highlighting, among others, legal sources, projects and political pedagogical perspectives in the current context.

Keywords: Youth and adult education. Restriction and deprivation of liberty. Reading in prison.
\end{abstract}




\section{Elionaldo Fernandes Juliáo}

E-mail: elionaldoj@yahoo.com.br

Jane Paiva

E-mail: janepaiva@terra.com.br

Recebido em: 23/12/2013

Versão final recebida em: 31/1/2014

Aprovado em: 7/2/2014 